\title{
Sacrococcygeal Teratoma in Adult Female: A Case Report and Review of Literature.
}

\author{
${ }^{1}$ Tabowei B.I., ${ }^{2}$ Udoye E.P , ${ }^{1}$ Mukoro D. George \\ MB.,B.S,FMCS. MB.,B.S,B.MED.Sc,Fmcpath. B.Sc,MB.,BS,DTM\&Hliverpool \\ 1.Department of Surgery, Niger-Delta University Teaching Hospital, Bayelsa, Nigeria \\ 2.Department of Anatomical Pathology, Niger-Delta University Teaching Hospital, Bayelsa, Nigeria.
}

\begin{abstract}
Adult Sacrococcygeal teratomas are very rare with female preponderance.
The manuscript is a review of this rare tumor presenting in adulthood and review of literature. We report a case of sacrococcygeal teratoma in an adult female complicated by acute urinary retention and intestine obstruction. She had a 26 year old mass at the same site excised 10 year before the current presentation. In conclusion sacrococcygeal teratomas are rare especially in adults and usually present in complicated state and with high incidence of recurrence.
\end{abstract}

Keywords: Adult, Sacrococcygeal, Teratoma.

\section{Introduction}

Sacrococcygeal teratomas are extremely rare in adults ${ }^{1}$ and present most frequently in infancy and childhood. The incidence in Nigeria is unknown, but in developed western world, It is put at 1:40,000 of all births with a female to male ratio of $10: 1^{2 \& 3}$. The most common site for extragonadal teratomas is the coccyx while sacrococcygeal teratoma remains the most frequent solid congenital tumor ${ }^{4 \& 5}$. Its etiology is yet unknown ,however, there are existing theories to explain it emergence ${ }^{6}$.We report a case of 37 year-old female with a recurrent sacrococcygeal teratoma managed in our hospital.

\section{Case Report:}

A.B, a 37 years old female trader, who was married with four children presented to our hospital with a four- year history of swelling in the gluteal region, loss of weight, difficulty passing stool and urine. The swelling increased in size gradually until six months prior to presentation when growth became aggressive, painful and was now associated with occasional fever. She had a similar tumor at the same site 10 years ago. This was excised at a tertiary health centre but the histopathology result was not known to her. Effort to get at previous report was not successful.

Physical examination revealed a young lady, restless, pale, anicteric and febrile to touch. Her chest was clinically clear, pulse rate was 80 beats per min, Bp 120/70 $\mathrm{mmHg}$ and she had fullness at lower abdomen with a suprapubic cystoctomy tube draining clear urine. She had a huge sacrococcygeal mass measuring $18 \mathrm{~cm}$ $\mathrm{x} 20 \mathrm{~cm}$ in dimensions. The right portion was grossly larger than the left with an old surgical scar of $5 \mathrm{~cm}$ long. Tumor was circumferential in shape, displacing and bridging the anal canal and vaginal orifice.

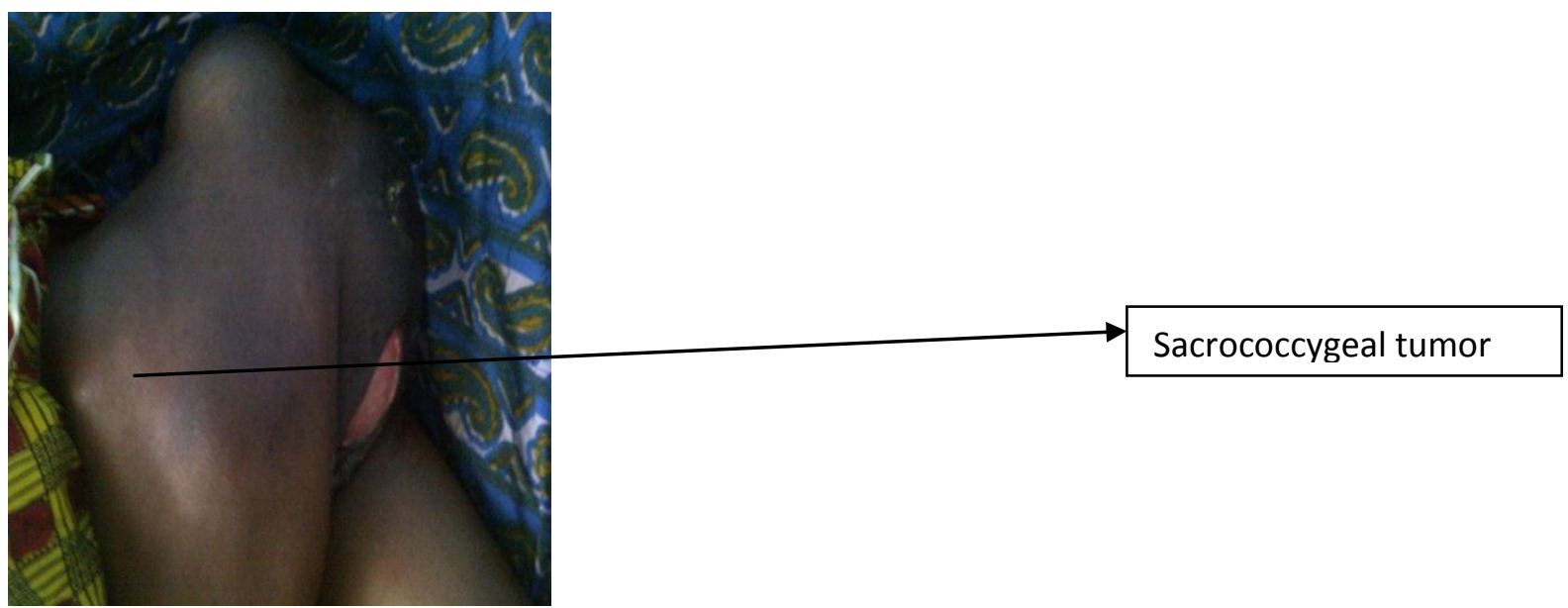

Figure 1:Right lateral view of the Lumbosacral and hip regions

The tumor surface was smooth, fixed to adjacent structures while both gluteal regions could not be demarcated. Tumor was tender to touch. A rectal and vaginal examination could not be done due to mechanical obstruction 
by the tumour. Based on the physical finding, the location of the tumor, an impression of sacrococcygeal teratoma was made. She was resuscitated with fluids.

The Pack cell volume was $20 \%$.Full blood count was $4.2 \times 10^{9}$ cells $/ u$ l, neutrophil was $60 \%$, monocyte was $15 \%$ while lymphocyte was $25 \%$. Serum electrolytes, urea and Creatinine were mildly deranged( $\mathrm{Na}^{+} ; 146$ $\mathrm{mmol} / \mathrm{l}, \mathrm{K}^{+}$4.8Urea $14.4 \mathrm{mmol} / \mathrm{l}$, Creatinine $277 \mathrm{umol} / \mathrm{l}$, chlorine $\left.{ }^{-} 116 \mathrm{mmol} / \mathrm{l}\right)$.Urinalysis showed amber and cloudy urine, severe and occult hematuria, pus cell of 1-8 per hpf. Fasting blood sugar was 99mg/dl. Ultrasound scan was not done due to financial constraint. X-ray of sacrococcygeal region showed a cystic mass without calcification.

\section{FIGURE 2. X ray film of Pelvic Region of the patient}

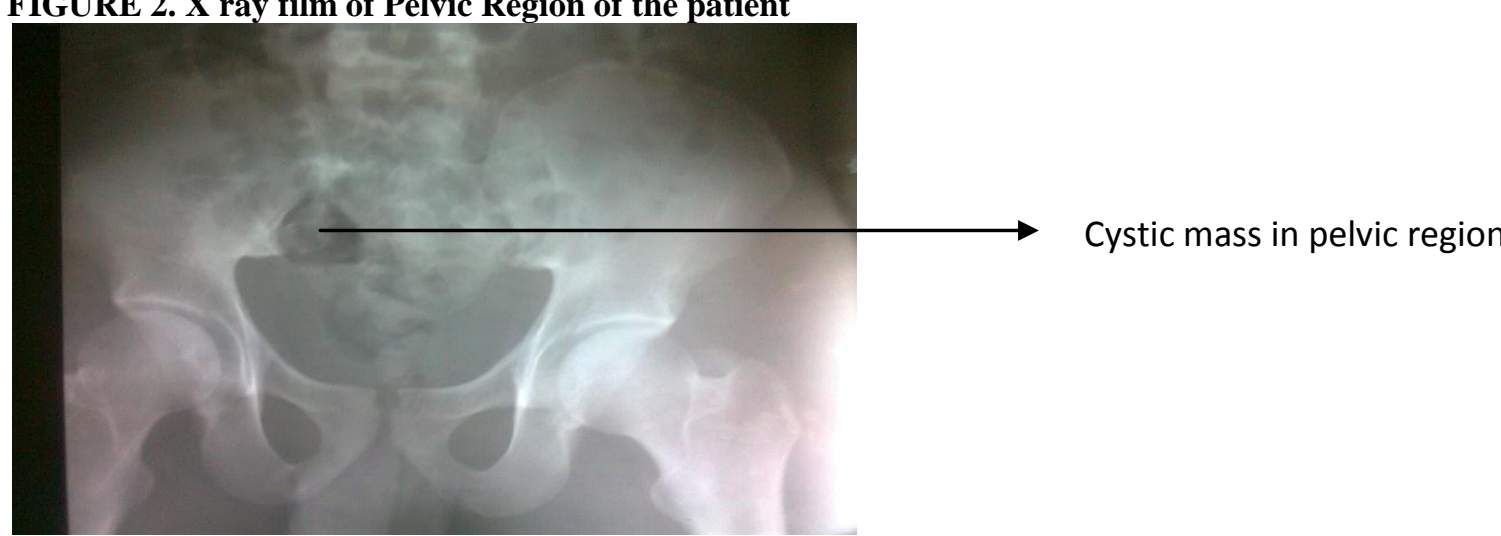

FIGURE 3: Sacrococcygeal region of the patient

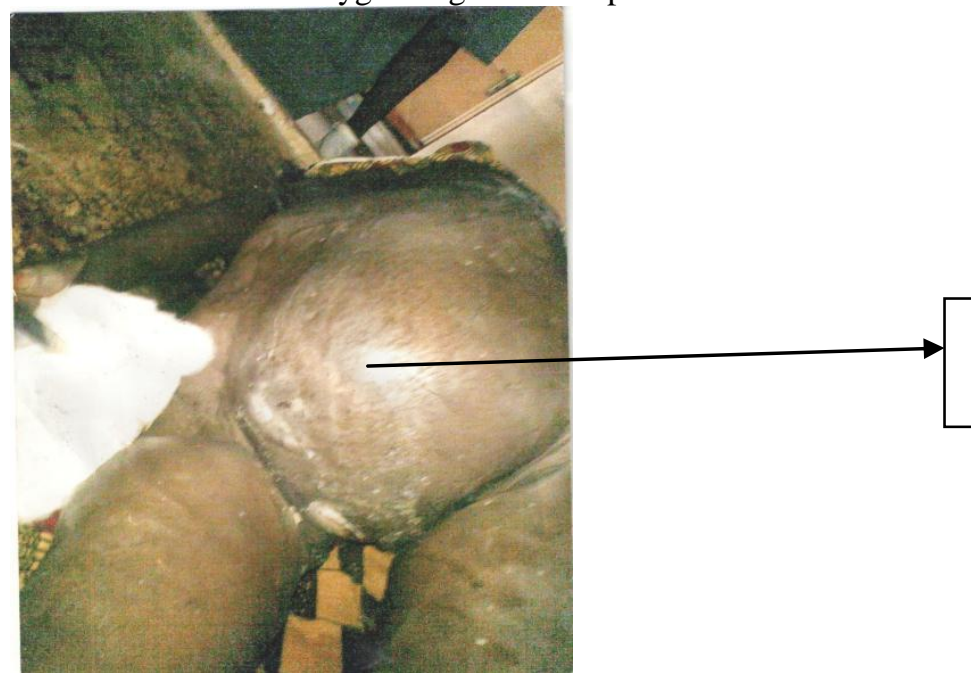

Tumour and both gluteal regions appear as single unit

Biopsy tissue for histopathologic evaluation showed multicystic spaces lined by cuboidal cells and having mature cartilage, matured nerve bundles, skeletal muscles, mature adipose tissues, blood vessels and bone spicules in its wall which is also infiltrated by chronic inflammatory cells. A histopathologic diagnosis of sacrococcygeal teratoma was made.

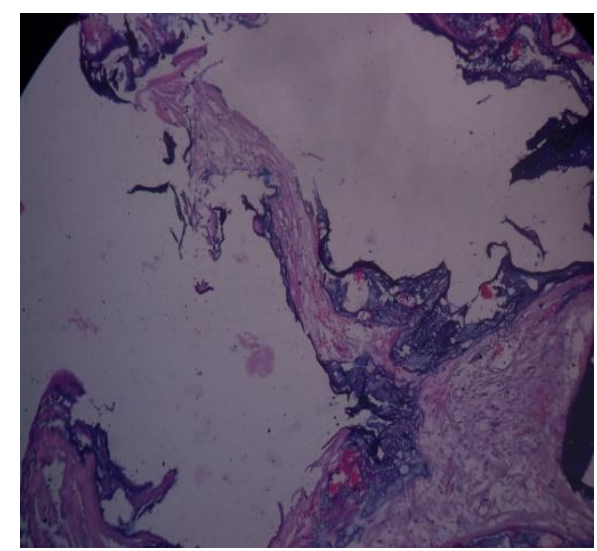

Figure 4: Photomicrograph of sacrococcygeal teratoma showing cystic spaces, lined by mature cartilages. 
Figure 5:Photomicroph of sacrococcygeal teratoma showing wall of the cystic space containing nerve bundles, cartilages and bony spicule.
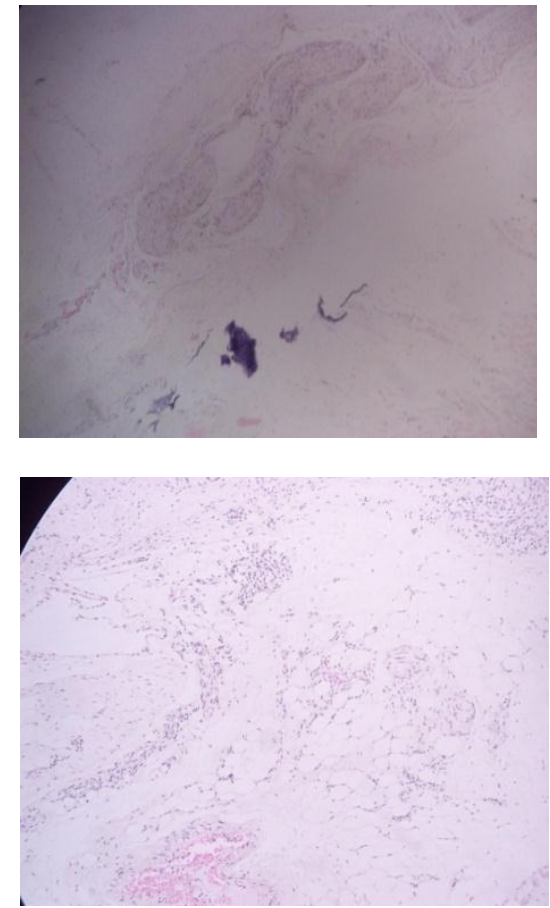

Figure 6:Photomicrograph of wall sacrococcygeal cystic teratoma showing mature adipose tissue and blood vessel with chronic inflammation .

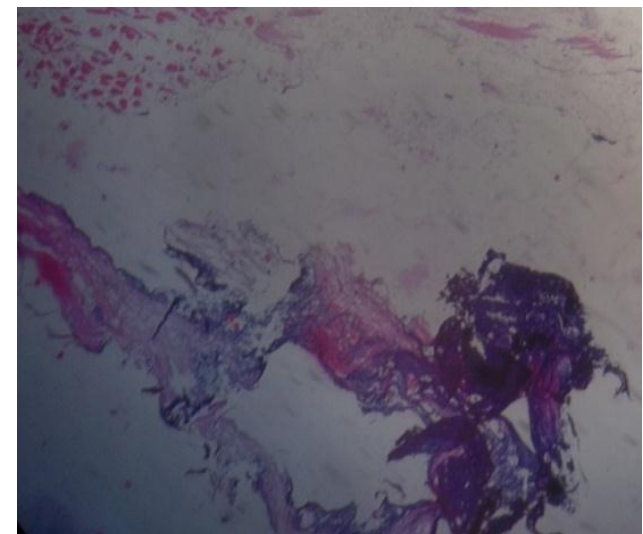

Figure 7:Photomicrograph of Sacrococcygeal teratoma showing cystic space line by cuboidal cells with mature cartilage ,mature adipose tissue and skeletal muscle in the wall of the cyst.

Patient's clinical condition deteriorated quickly. She could not pass stool nor pass urine until she died at the $3^{\text {rd }}$ day from admission. It took over 26 years for the first tumor to be excised. The second tumor started 4 years after previous excision and was excised 6 years later.

\section{Discussion}

Sacrococcygeal teratomas are extremely rare in adults ${ }^{1}$,in-fact sacrococcygeal presentation in adult is deemed exceptional ${ }^{7}$. The incidence of this tumor in Africa is unknown, but in the western world it is put at 1 : $35000-40,000$ at birth, with female to male ratio of $10: 1^{2 \& 3}$. Seventy-five to ninety percent of sacrococcygeal germ cell tumors occur in females ${ }^{8}$. The coccyx is the most common site for extragonadal teratomas which also is the most frequent solid congenital tumour in infants ${ }^{4 \& 5}$. The etiology is unknown ${ }^{6}$, however, there are existing theories to explain the emergence of these tumours in the sacrococcygeal areas .These include derivation from multipotent cells in the Henson's nodes which migrate caudally to rest in the coccygeal sites or wandering germ cells of non-pathogenetic origin that have been left behind during the migration of embryonic germ cells from the yolk sac to gonads or originated from other totipotent embryonic cells ${ }^{9 \& 10}$. Chromosomal analysis of these extragonadal teratomas suggest that they have arisen from postmitotic premeiotic cells ${ }^{11}$. In this index case, the aetiopathogenesis is not apparent. 
Most of the sacrococcygeal tumours are cystic and benign and only $1-2 \%$ are malignant ${ }^{8 \& 12}$. Histopathologic evaluation strongly suggested that the index case was benign. Though, the patient had history of grossly similar mass excised from the same site, histologic evidence showed a benign tumor in in this subsequent mass at same site. This is not unusual, as it is known that mature teratomas excised early in life may recur in adulthood in the form of microscopically similar neoplasm ${ }^{13}$.However, the recurrence in adulthood can also be as a malignant giant cell tumor( such as yolk sac tumor) ${ }^{14}$ or a somatic type malignant tumor (such as adenocarcinoma $)^{15}$.The tumour may grow posterior-inferiorly into the gluteal area ${ }^{\text {fig } 3}$ and or inferior-superiorly into the abdomino-pelvic cavity ${ }^{4}$ as was demonstrated in this index case ${ }^{\text {fig } 1 \& 3}$. There is a tendency of the tumor of becoming malignant with advancing age ${ }^{16}$.

It has been observed that sacrococcygeal teratomas associated with marked bowel and bladder dysfunction are often malignant ${ }^{8}$.The index case presented with inability to pass stool, urinary retention and mild serum electrolyte derangement. These findings are expected in our patient who had a huge tumor protruding through the abdominal cavity and tearing the anterior abdominal wall ${ }^{\text {(fig } 1)}$.

Differential diagnosis of sacrococcygeal teratoma in adults include variable pathologies such as anterior meningocele, rectal or anal duplication cyst, anal gland cyst, seroma or urinoma ${ }^{17}$. Also in the presence of multiloculated cystic lesions, it may be a trail gut cyst (retro-rectal cystic harmatoma) ${ }^{17 \& 18}$. Clinically, the physical characteristics of the tumour fig1\&3 in this index case suggested a huge cystic mass before the histopathological diagnosis was made.

Computed tomography scan and MRI are helpful diagnostic tools, however these are often not available in our environment, and in most cases are not affordable to the cadre of patients most often involved in such disease. It has been suggested that sacrococcygeal teratomas are disease of the lower socio-economic class and ignorance ${ }^{19}$.This is exemplified in the index case where it was difficult to carry-out some investigations including pelvic ultrasound scan due to unavailability of finance.Furthermore, the first tumor was carried for 26 years before seeking medical help and it is also possible that histopathologic analysis may not have been carried-out due to financial reasons.

The treatment of choice is early and complete excision with cococcygectomy ${ }^{2,7,10 \& 20}$.In the index, excision of the tumour was done at an early age, but may have been incompletely excised, thus the suggested recurrence. Surgical approach depends on the size and the topographic location of the tumour ${ }^{16 \& 20}$. Our patient most probably died of the combine effect of electrolyte imbalance, sepsis and anaemia.

\section{Conclusion:}

Sacrococcygeal teratomas are rare in adults, and should be suspected in adults presenting with lowerback tumours. Histopathological evaluation of such tumours among other ancillary radiological investigations should be done.

\section{References:}

[1]. Abubakar Am,Nggada HA,Chinda JY. Sacrococcygeal tetratoma in Northeastern Nigeria:18 year experience .Pediatr Surg Int 2005, 21;645-648 (pubmed Abstract)

[2]. M. Monteiro, TM Cunha, A Catarino, V Tome : Sacrococcygeal teratoma with malignanttransformation in an adult female :CT and MRI findings.

[3]. Valdiserri RO, Younis EJ. Sacrococcygeal teratoma: a review of 68 cases cancer 1981; 48:217-221.

[4]. Ajuwape O.O., Ogundoyin O.O., Ogulana D I, Adeleye A.O.;Adult Sacrococcygeal teratoma: A case report Ghana Med J. 2009 March; 43(1); $40-42$.

[5]. Harbon S,Pheline y.Grant sacrococcygeal teratoma in adult.Ann Chir Esthet:1989,34:153-159

[6]. Ghosh J, Eglinton T, Frizelle FA, Waston AJ:Presacral tumour in adults.Surrgeon.2007;5(1):31-38

[7]. Ng EW, Porcu P, Loehrer PJ Sr, Sacrococcygeal teratoma in adults; case reports and a review of the Literature. Cancer 1999, 86:1199-1202.

[8]. Juan Rosai: Sacrococcygeal region; germ cell tumors .in Rasai and Ackerman's Surgical Pathology. $9^{\text {th }}$ Ed ,2:2401-2.

[9]. Audet IM, Goldhahn RT, Dent TL,Adult sacrococcygeal teratomas.Am surg. 2000;66(1):61-65.

[10]. Mahour GH,Sacrococcygeal teratomas. CA Cancer J Clin .1988;38(6):362-367.

[11]. Kaplan C G,Askin FB Benirschke K. Cytogenetics of extragonadal tumors.Teratology 1979:261-266

[12]. Chene G, Voiltellier M.Begnign Presacral teratomas and Vestigial rectrorectal cyst in the adult.J Chir(Paris),2006,143(5);310-314

[13]. Lahdenne P,Heikinheimo M,Nikkanem V,KLemi P,Simes MA,Rapola J.Neonatal Benigh Sacrococcygeal teratoma may recur in adulthood and give rise to malignancy cancer 1993,72:3727-3731

[14]. Addis BJ ,Rao SG ,Finnis D,Carrell JE.Pre-sacral carcinoid tumor.Histopathology 1991,18.563-565.

[15]. Lack E E,glaun RS,Hefter LG,Seneca RP,Steignan C,AlhanF.Late occurrence of malignancy following resection of histologically mature sacrococcygeal teratoma.Report of a case and literature review.Arch Pathol Lab Med 1993,117:724-728.

[16]. Ahmed HA, Pollock DJ, Malignant sacrococcygeal tetratoma in the adult. Histopathology 1985;9:359-63.

[17]. Keblar PJ, Buck JL,Suarez Es. Germ cell tumour of the sacrococcygeal region; radiologic-pathologic correlation.Radiographus 1994;14:607-20.

[18]. Green Dm, Tarbel NJ,Schamerger RC,Solid tumour of the childhood-germ cell tumour.In De Vita JT Jr,Hellmans,Rosenberg SA, editors.Cancer;Principles and practice of Oneology Philadelphia PA.Lippincoll Raven 1997:2118-20.

[19]. Ozoilo KN,Yilkudi MG,Ede JA Sacrococcygeal teratoma in an adult female Nigerian.Ann Afr Med 2008;7:149-50

[20]. Localio SA,Eng K,Ranson JHC. Abdomino-sacral approach for retrorectal tumours.Am Surg $1980 ; 191: 555-60$ 